\title{
Study on Impact of New Energy Wind Power Access to Electric Power System
}

\author{
Yinping Zhou
}

North China Electric Power University, School of Electrical and Electronic Engineering, Beijing, 102206

Keywords: New Energy; Wind Power; Power Grid

\begin{abstract}
Wind power technology is currently the world's fastest growing and has the most economic benefits of all kinds of renewable energy generation technologies, but the randomness and intermittent of the wind speed and will directly affect the wind farm output. In this paper, the impact of new energy wind power access to electric power system is analyzed, including power quality, operation, grid planning and reactive power allocation, and then the solutions are proposed to promote wind farm access to power grid.
\end{abstract}

\section{Impact of New Energy Wind Power Access to Electric Power System}

\section{A. Impact on System Power Quality}

Power quality index of electric power system mainly include voltage deviation, frequency deviation, voltage fluctuation and voltage flicker, etc. The wind farm connected with power grid may cause fluctuations in the power grid voltage, and then cause a noticeable flicker. The main reason is the random variation of wind speed, as well as the influences because of some inherent characteristics of wind turbine itself, such as wind shear, tower shadow effect, gravity blade and yaw deviation error, etc. In addition, the variable speed wind turbine with power electronic converter can also inject harmonic currents into the power system, thus cause the harmonic distortion of the power network voltage.

In view of the above problems, we should install the dynamic reactive power compensation device of a certain capacity in wind farm, and carry out real-time adjustment on network voltage level, so as to make sure that the network power quality to meet the relevant requirements.

\section{B. Impact on Safe and Stable Operation}

Induction generators are widely used in wind farm. Grid-connected wind farm can be regarded as connecting a reactive load into power grid, so taking into account the line reactive power loss and the reactive power demand of wind farm itself, it will lead to less reactive of system. Frequency and voltage stability are the main indicators to measure the safe and stable operation of power grid. In order to ensure the stability of the system, after the wind farm is connected to the power grid, it requires reactive power generation capability, which can be realized by active wind farm.

In view of the above problems, we should install fault splitting, step splitting and frequency voltage emergency control devices, to ensure the stability of grid.

\section{Impact on Scheduling System}

After wind farm integration, its output is likely to be the opposite of the load characteristic curve, that is, there is no output during peak load in the daytime, while full output during low load at night, which is described as anti-peaking characteristics. The Peak load capacity of system is affected by wind power output characteristics, power structure, load characteristics, power grid structure, market and economic environment, etc. The schematic diagram of wind power system is shown as Figure 1: 


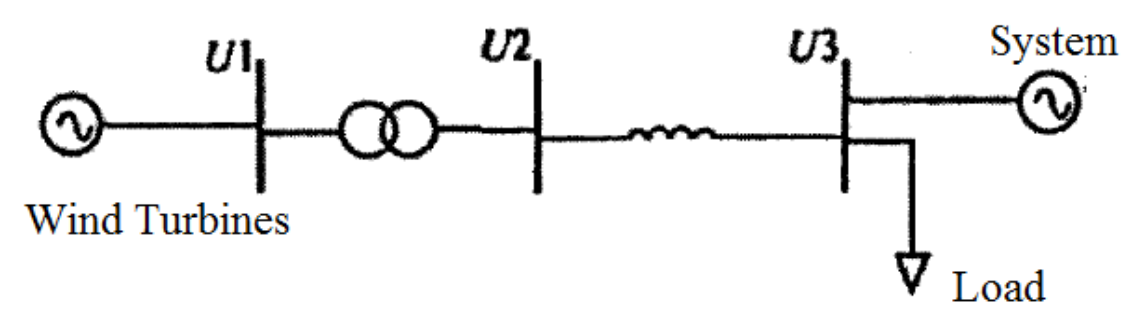

Figure 1. Wind Power System

We can conclude from the figure above, if there is no wind farm, the flow will be unidirectional, and as the distance increases, the flow decreases. With the integration of wind farm, the system flow comes to be unpredictable. Uncertainty of load flow direction will affect the adjustment of voltage level, and even make the system high pressure equipment abnormal reaction.

In view of the above problems, we need to install wind power forecasting system in wind farm, which could support short-term wind power prediction of 0 48 hours and ultra-short-term wind power prediction of $0.25 \sim 4$ hours. With the construction of wind power forecasting system, grid scheduling department is able to conduct effective scheduling and scientific management on wind farm, to improve the capacity of power grid to accept wind power, and reasonably arrange the generation plan of the whole power grid.

\section{Impact on Power Grid Planning}

Due to the characteristics of wind power resource distribution, the site surrounding wind farm is like to have weak power grid structure. Fortunately, due to the early capacity of the grid connected wind farm is generally small, with voltage level of $110 \mathrm{kv}$ and $35 \mathrm{kv}$, so it has little influence on power network planning. However, with the development of wind turbine technology and the improvement of the national energy saving and emission reduction requirements, the scale of wind farm construction in planning is increasing, as well as the increase of access distance, it requires us to make special planning for large wind farms. Meanwhile, taking into account the randomness and uncertainty of wind power, it also needs to meet the requirements of local resource allocation optimization.

\section{E. Impact on Reactive Power Allocation}

Firstly, grid-connected wind farm have to consider the problem of reactive power allocation to the wind farm. The sum of the reactive power compensation device capacity wind farm should be not less than $50 \%$ of the installed capacity of wind power. On the one hand, it requires wind turbines themselves have reactive power generation capability; on the other hand, in the low-pressure side of the wind farm, should install centralized reactive power compensation devices used for compensation transformer, wind power exporting line and collector circuit.

From the current actual operation experience of the wind farm, if just rely on reactive power generation capability of wind motor itself, wind farms still need to absorb reactive power from the system, and could not meet system voltage regulation requirements.

In view of the above problems, we firstly need to take advantage of the reactive power and regulation capacity of wind turbine; then set aside some means for the operation of the power grid, in order to make sure that the capacity of centralized reactive compensation in wind farm is not less than $20 \%$ of the installed capacity of wind power.

\section{The Solution to Wind Farm Access to Power Grid}

\section{A. Networking Solutions}

There are two main types of networking solutions, which may be used in the wind farm, including AC transmission and DC transmission. Currently, AC transmission is widely used in wind farm grid connected power supply system; while for long distance transmission and offshore wind farm, DC transmission could also be considered. AC transmission has high efficiency in 
short-distance transmission, while DC transmission is better in long-distance transmission. AC transmission and DC transmission solutions of wind farm are shown in Figure 2 and Figure 3:

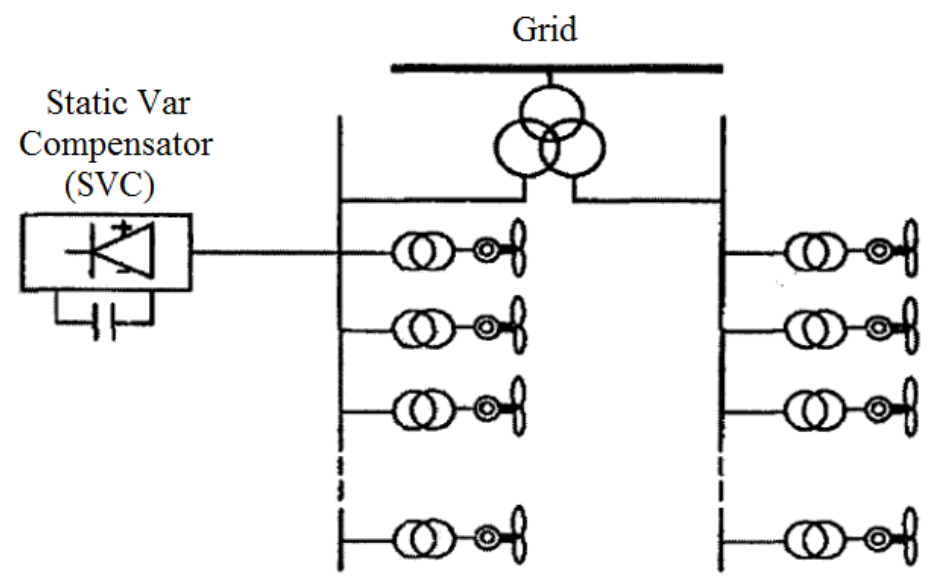

Figure 2. AC Transmission Solution of Wind Farm

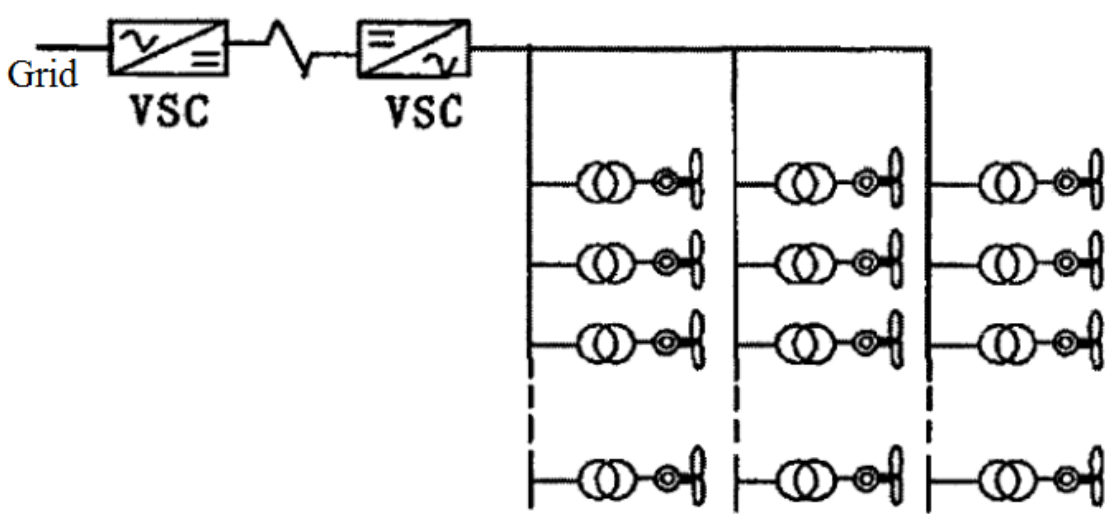

Wind power generator

Figure 3. DC Transmission Solution of Wind Farm

\section{B. Access Means}

According to the construction sequence and area distribution of wind farm, access means of wind farm could be divided into decentralized access and centralized access.

(1) Decentralized Access

a) Single point access: the decentralized access method for single point injection could reduce the effect on the voltage quality and the power quality of a single substation, and meanwhile it is conducive to the realization of local power supply, to avoid power flow and reduce network loss. The schematic diagram of such access means is shown in Figure 4:

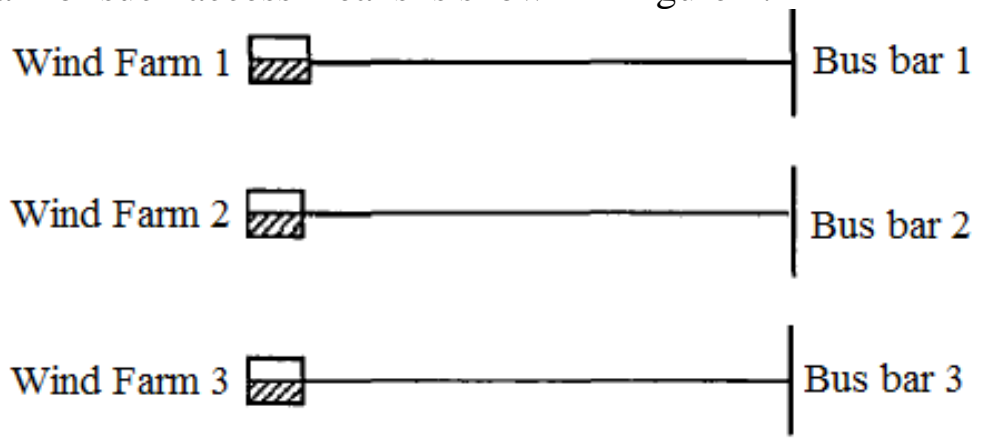

Figure 4. Single Point Access Means

b) $\mathrm{T}$ access: in case of restricted bus station interval, weak grid supporting or difficult to select route path, have to adopt the $\mathrm{T}$ access mode in which two or more wind farms share a return line. Under the premise of stable power change, such access means could greatly reduce the area of wind power transmission project construction and the amount of investment. The schematic diagram of $\mathrm{T}$ access means is shown in Figure 5: 


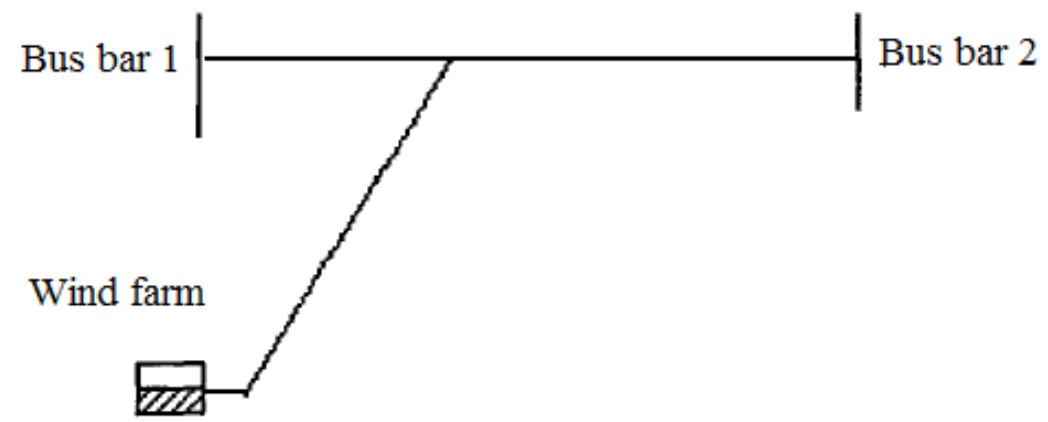

Figure 5. T Access Means

(2) Centralized Access

For the district where the wind power installed capacity is concentrated, in case of many wind farms, we can consider to set several wind farms connected to the grid, so as to save grid investment and convenient for operation and management of power grid. Centralized access of wind farm is mainly used for $220 \mathrm{kv}$ or above. The schematic diagram of centralized access means is shown in Figure 6:

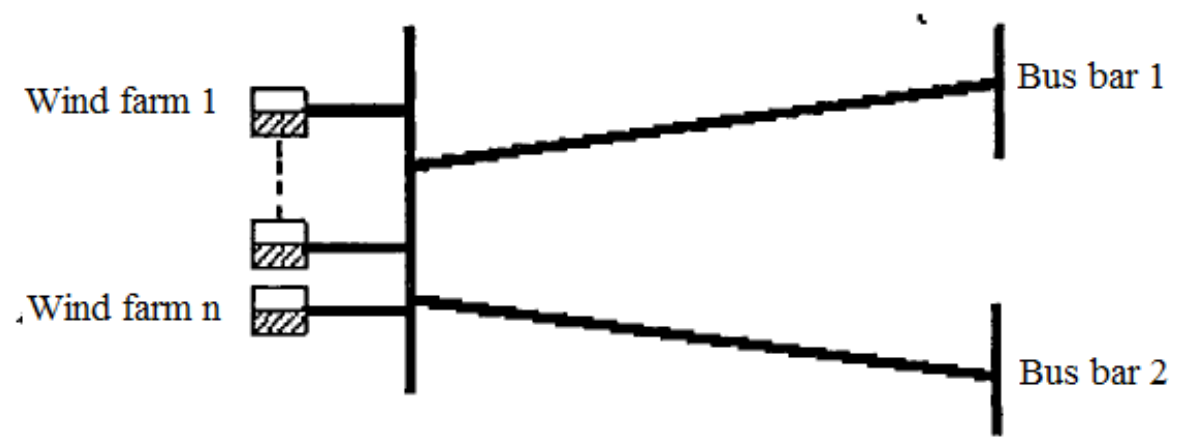

Figure 6. Centralized Access Means

\section{Conclusion}

With the large-scale construction of wind farm, its ratio of total grid generation capacity is increasing. We carry out the study on the impact of wind power access to electric power system, which is mainly reflected in power quality, grid operation, grid planning and reactive power allocation. And in view of the various aspects of the impact, we propose put forward some corresponding improvement measures, so as to reduce the impact of its access to the power grid.

In addition, In order to achieve better wind farm access, we propose some suggestions. In terms of networking mode, we make a comparison between AC transmission and DC transmission networking mode, and summarize their features and adaptation scene; in terms of access means, decentralized access and centralized access means are introduced.

\section{REFERENCE:}

[1] Abdel-Karim N. Effects of integrating wind power for representative load scenarios in a us electric power system: Operational costs and environmental impacts[C]// Environment and Electrical Engineering (EEEIC), 2010 9th International Conference on. IEEE, 2010:186 - 189..

[2] Shi B Z, Macdowell J, Piwko R, et al. New Progress of Technology for Wind Power Access to Power Grid[J]. Electrical Equipment, 2008.

[3] Maaji S S, Khan D F S, Haldar M K, et al. Integration of Solar and Wind Power to a Borneo-wide Power Grid[J]. International Journal of Environmental Science \& Development, 2013, 4(2013). 
[4] Manoj S, Puttaswamy P S. Effective Integration of Wind-Distributed Generation to Power Grid with STATCOM[M]// Emerging Research in Electronics, Computer Science and Technology. Springer India, 2014:877-889. 3.

[5] Wallnerstrom C J, Huang Y, Soder L. Impact From Dynamic Line Rating on Wind Power Integration[J]. IEEE Transactions on Smart Grid, 2015, 6(1):343-350..

[6] Cai Z, Zhao H T, Men D Y, et al. Security Constrained Dispatch Based on Wind Power Concentrated Access[J]. Advanced Materials Research, 2013, 805-806:424-429. 